\title{
Weniger Krebstote
}

Alle Krebsentitäten zusammengenommen, starben im Jahr 2011 knapp 102.000 Frauen bzw. 120.000 Männer an einer Tumorerkrankung. Das sind die aktuellsten Daten, Ende 2015 gemeinsam veröffentlicht vom Bund und dem Robert-Koch-Institut (RKI)*. Verglichen mit 2001 liegen die nackten Zahlen höher - bei den Frauen um 2,6\% und bei den Männern um 10,5\%. Aber unter Einbezug des demografischen Wandels ergibt sich ein anderes Bild: Gegenüber 2001 liegen die altersstandardisierten Mortalitätsraten um 7,8\% bzw. 11,7\% niedriger. Die Veränderungen im Detail zeigt unten stehende Grafik. Unverändert bleiben Krebserkrankungen in Deutschland die zweithäufigste Todesursache - nach den Herz-Kreislauf-Erkrankungen.

Martin Roos

Absolute Mortalität bei Männern und Frauen im Jahr 2011

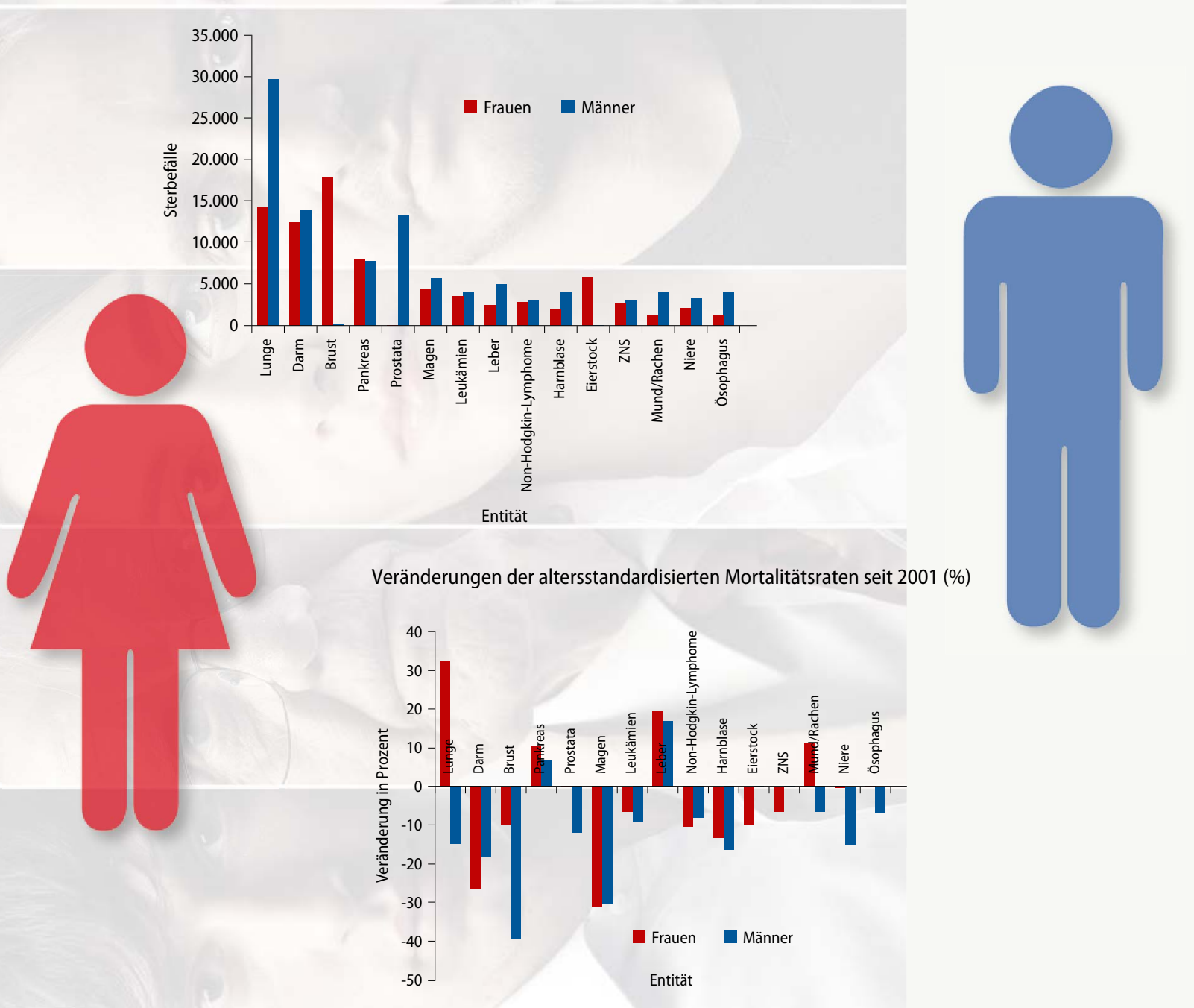

* Mit "Gesundheit in Deutschland" stellten Bundesministerium für Gesundheit und RKI Anfang Dezember 2015 nach 1998 und 2006 zum dritten Mal eine umfassende Darstellung zu Gesundheitszustand, Gesundheitsverhalten und Gesundheitsversorgung der Bevölkerung in Deutschland vor. In diesen Aspekten gibt es demnach zwischen alten und neuen Bundesländern kaum noch Unterschiede. Abrufbar ist der gut 500 Seiten umfassende Bericht unter tinyurl.com/RKI-Bericht 